\title{
Proper nutrition can prevent negative health outcomes in young female athletes
}

by Michelle T. Barrack and Marta D. Van Loan

Since the onset of Title IX, opportunities have dramatically increased for female athletes, largely to their benefit. However, some negative health outcomes such as disordered eating, chronic menstrual disturbances and low bone mass have been associated with high-level competition among some female athletes, particularly in sports such as gymnastics and cross-country running, where a slender physique or lean body build is important. Adolescent female athletes, in a rapid growth and development phase, may be at greatest risk. We sought to identify athletes at risk, understand the origin of possible negative outcomes and recommend behavioral modifications that promote participation in competitive sports while supporting lifetime health. This review discusses the development and impact of disordered eating and menstrual dysfunction on bone mass in young, competitive, female athletes and provides nutrition recommendations for their energy, carbohydrate, protein, vitamin and mineral intake.

$\mathrm{T}_{\mathrm{g}}^{\mathrm{h}}$ he arena of competitive sports for girls and young women was transformed by Title IX of the Education Amendments of 1972, which states, "No person in the United States shall, on the basis of sex, be excluded from participation in, be denied the benefits of, or be subjected to discrimination under any education program or activity receiving Federal financial assistance."

In 1971, male competitors outnumbered females by more than five-to-one in college sports and more than twelve-toone in high school sports (NCWGE 2008). Due to regulations set forth by Title IX, the number of female competitors in the

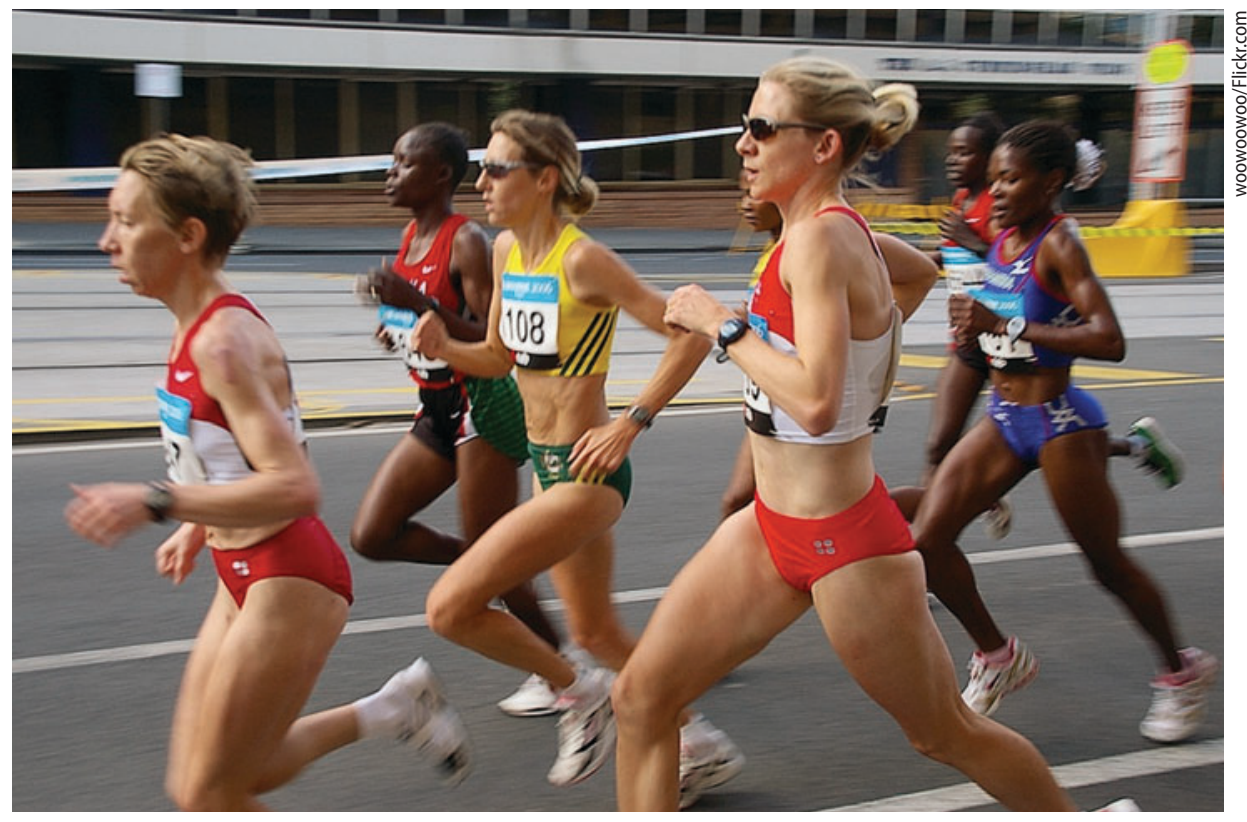

Girls and young women who participate in endurance sports such as long-distance running may suffer negative health outcomes as well as positive ones. They may have a higher risk of low bone mass, menstrual disturbances and disordered eating.

National Collegiate Athletic Association (NCAA) increased more than 4.5-fold (from fewer than 30,000 to nearly 167,000) between 1971 and the 2004-2005 academic year (NCWGE 2008). Female high school athletic participation in the United States increased to a greater extent, from 300,000 in 1972 to over 2,950,000 in 2006 (NCWGE 2008). In 2009, there were nearly 300,000 female competitors in the California Interscholastic Federation alone (CIF 2009).

Athletic involvement by girls and young women has resulted in many positive health, cognitive, psychological and behavioral benefits. Research shows that regular exercise increases overall strength and aerobic fitness, improves cardiovascular health and lowers the risk of chronic degenerative diseases such as atherosclerosis and diabetes (Haskell et al. 2007; Hasselstrom et al. 2002; Kemper et al. 1999). For girls, sports participation enhances self-esteem and self-efficacy and reduces feelings of depression (Colton and Gore 1991). Various reports document higher academic performance, cognitive function and degree completion rates among girls and young women who engage in competitive sports (NCAA
2005). Furthermore, the use of tobacco and drugs, as well as sexual promiscuity, is lower among female athletes (Kulig et al. 2003).

Despite the many benefits, involvement in some sports - particularly those where a slender or lean body type (having less body fat) is important - has been associated with a higher risk of developing certain negative health outcomes. Girls and women participating in gymnastics and endurance sports such as crosscountry running have demonstrated low bone mass, particularly at the lumbar spine; menstrual disturbances, including fewer cycles or no cycle (amenorrhea); and a high prevalence of disordered eating (Beals and Hill 2006; Nichols et al. 2007; Torstveit and Sundgot-Borgen 2005a).

\section{Female athlete health issues}

Beals and Hill (2006) reported the eating attitudes and behaviors, menstrual function and bone mass of 112 female U.S. collegiate athletes. The authors observed

Online: http://californiaagriculture.ucanr.org/ landingpage.cfm?article=ca.v065n03p124\&fulltext=yes DOI: 10.3733/ca.v065n03p124 
that compared to other athletes, those with slender/lean body types had higher frequencies of moderate to extreme body dissatisfaction and binge eating, and a trend $(P=0.08)$ toward a higher frequency of self-described eating disorders. Slender or lean female athletes also exhibited a higher prevalence of menstrual irregularity (cycles less than 28 days, nine or fewer cycles per year or no cycle at all) and lower bone mass.

Low bone mass. Low bone mass in young women can lead to the early onset of osteoporosis and increased risked for bone fractures. Mudd et al. (2007) compared data from 99 female collegiate athletes participating in 12 different sports and found that endurance runners had lower bone density throughout the body and particularly at the lumbar spine, compared to gymnasts and softball players, while swimmers exhibited significantly lower bone density in their legs compared to athletes in all other sports. Additionally, approximately $40 \%$ of collegiate or postcollegiate (Cobb et al. 2003) and adolescent endurance runners (Barrack et al. 2008) had low bone mass for their ages.

Menstrual irregularity. Adequate reproductive hormones, especially estrogen, are needed for bone mineralization during adolescence and for continued bone maintenance thereafter. Up to $66 \%$ of female competitive endurance runners exhibit menstrual irregularities, and $40 \%$ have low bone mass (Barrack et al. 2008; Cobb et al. 2003; Gibson et al. 2004; Warren and Chua 2008). These rates are about three to five times higher than reported estimates of these same conditions in healthy young women and girls who do not run competitively (van Hooff et al. 1998).

Gibson et al. (2004) observed a $66 \%$ prevalence of menstrual irregularity among 50 elite female endurance runners. In a sample of 423 California high school athletes, Nichols et al. (2007) found that girls participating in sports that benefit from a lean or slender body type had a higher prevalence of menstrual irregularity $(26.7 \%$ and $16.6 \%$, respectively; $P<0.005)$ compared to athletes in other sports but no increased evidence of disordered eating.

Eating disorders. Eating disorders have been shown to disrupt the menstrual cycle, resulting in low or no estrogen production. Adequate levels of estrogen are needed to increase bone mineralization and, in turn, bone density. In a sample of 300 female collegiate cross-country runners, Thompson (2007) reported that $19.4 \%$ either currently or previously had an eating disorder, while Hulley and Hill (2001) found that $16 \%$ of their sample of elite women distance runners had a current eating disorder. These estimates are considerably higher than the $0.5 \%$ to $2 \%$ occurrence of anorexia or bulimia nervosa in the population of young, healthy, adult female noncompetitive runners (Academy of Eating Disorders 2011).

Furthermore, among a sample of collegiate athletes, young women involved in aesthetic sports such as cheerleading, diving and gymnastics (lean or slender body-build sport types) had the lowest body weight and highest scores on the Eating Attitudes Test, which is indicative of abnormal eating attitudes and behaviors such as dietary restraint, in which the individual restricts food intake to control body weight (Beals and Manore 2002).

Female Athlete Triad syndrome. These interrelated conditions (eating disorders, amenorrhea and osteoporosis) were first officially recognized and defined as the "Female Athlete Triad" by the American College of Sports Medicine Task Force on Women's Issues in 1993 (Yeager et al. 1993).

Subsequent epidemiologic studies found that among female athletes, the prevalence of all three aspects of this triad was low (about 1\% to 3\%) (Beals and Hill 2006; Cobb et al. 2003; Nichols et al. 2006). Several studies identified a portion of girls with menstrual disturbances but no eating disorders, and a portion of girls with low bone mass but no clinical menstrual disturbances (Hilton and Loucks 2000; Torstveit and Sundgot-Borgen 2005b). This prompted more research to better understand the causes of exerciserelated low bone mass and menstrual disturbances in female athletes.

\section{Energy deficit vs. exercise stress}

An important question is whether these exercise-related health problems occur from an energy deficit, in which calories consumed do not meet calories needed for the increased level of physical activity, or from excess stress that alters the hormones regulating menstrual function and bone metabolism. Several well-controlled animal and human experimental studies have confirmed that as long as energy is available for physiological needs other than exercise, it promotes normal hormone function. This suggests that intense exercise does not in itself exert an additional stress that disrupts menstruation and bone metabolism.

Williams et al. (2001) trained a group of female monkeys to do 2 hours of endurance exercise (running) per day. The resulting energy deficit caused the complete cessation of their menstrual cycles. But once the monkeys were fed adequate calories to adjust for the increased energy expended on their endurance exercise regime, normal menstrual function gradually resumed over a period of 12 to 57 days. These findings demonstrate the critical role of energy in maintaining normal hormonal levels and menstrual function during exercise.

Ihle and Loucks (2004) evaluated the roles of energy deficiency and exercise stress on hormone concentrations that regulate bone metabolism by examining markers of bone turnover in 29 healthy, moderately active young women. First, the women spent 2 months on a balanced diet and exercise regimen that required about $25 \%$ of their energy intake. Then

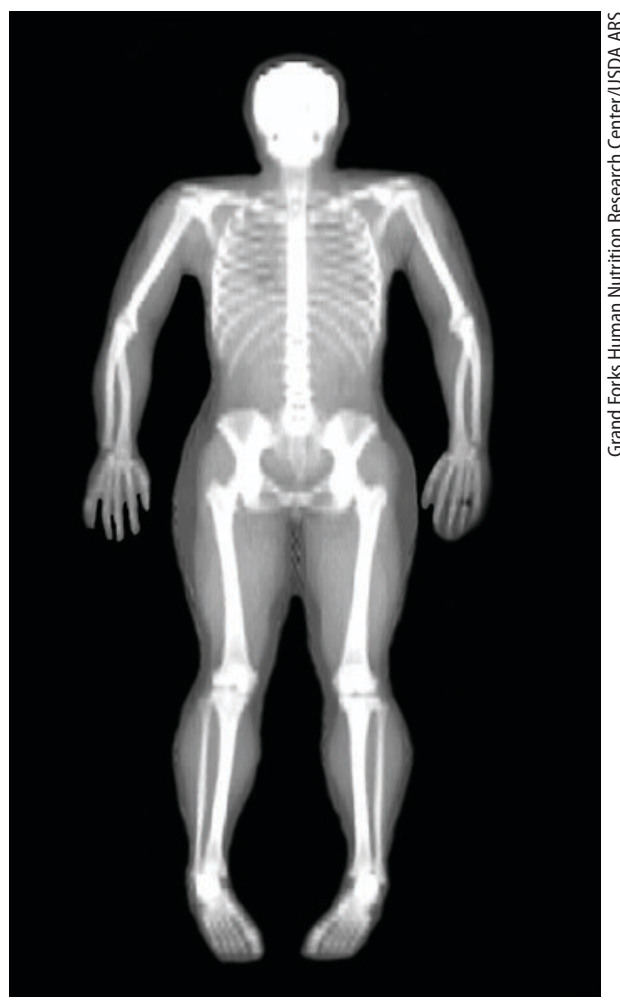

An insufficient diet restricts the amount of energy available for metabolic processes. The deposition of bone may subsequently be reduced, and bone resorption increased. 


\section{For optimal health and peak performance, it is critical to consume the three primary macronutrients for energy metabolism (carbohydrates, protein and fat) as well as a multitude of micronutrients (vitamins and minerals).}

\section{Menstrual disturbances, low bone mass}

Menstrual disturbances have long been established as risk factors of low bone mass. While it was previously hypothesized that psychological or physiological stressors caused at least some cases of menstrual dysfunction, accumulating evidence indicates that most if not all menstrual disturbances in female athletes are preceded by an energy deficit due to dietary restriction or excessive exercise without adequate nutritional replenishment (Ihle and Loucks 2004).

Converging evidence from previous research studies has documented the direct effect of energy deficits on hormonal secretions from the pituitary gland, which controls many endocrine functions, including growth hormone production and the regulation of ovulation, as well as estradiol synthesis, all of which are needed for optimal bone mineralization and the attainment of peak bone density (Loucks 2006). Menstrual disturbances do not appear to cause low bone mass; rather, they are a sign of underlying hormone dysregulation, which may also negatively affect bone metabolism.

In addition, reduced bone mass can be associated with energy deficits that lower hormonal secretions, resulting

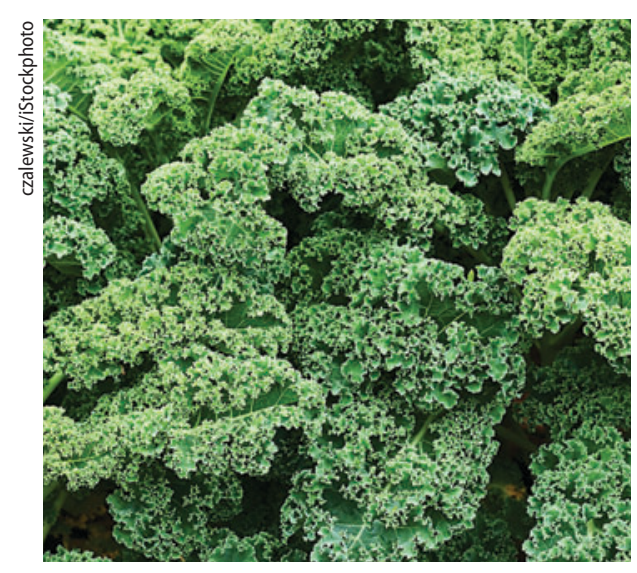

Antioxidants, found in vegetables such as kale, protect against oxidative cell damage and are important for high-intensity aerobic athletes. in anovulation and other subclinical menstrual disturbances that often go unnoticed (McLean et al. 2001). Therefore, clinical menstrual function may not be an adequate signal of underlying hormone disruptions and associated bone-related risks. Because individuals with seemingly normal menstrual function may also be at risk of disrupted bone metabolism and consequently low bone mass, it is important to identify a proxy measure of low energy availability.

\section{Macronutrients for female athletes}

Proper nutrition influences sport performance and overall health by, for example, reducing injury risk while increasing energy levels, recovery time and immune function. Given the high activity levels of athletes, their requirements for some nutrients are higher than those of the general population. It is important for female athletes to be aware of their unique requirements and maintain diets that satisfy their specific needs.

Just consuming enough energy (calories) is not enough. For optimal health and peak performance, it is critical to consume the three primary macronutrients for energy metabolism (carbohydrates, protein and fat) as well as a multitude of micronutrients (vitamins and minerals).

Energy. Consuming adequate energy is necessary to support high-intensity or endurance exercise. The 2005 Institute of Medicine Dietary Reference Intake report provides energy intake recommendations for all ages, but these should be carefully defined for each athlete based on age, development stage, activity level and proportion of lean tissue mass (IOM 2005)

Carbohydrates. Carbohydrates are important components of an athlete's diet, particularly an endurance athlete's. Besides being a primary macronutrient for energy metabolism, carbohydrates are needed to efficiently maintain the muscle glycogen that athletes use as fuel for vigorous exercise. It is recommended that athletes consume a high-carbohydrate

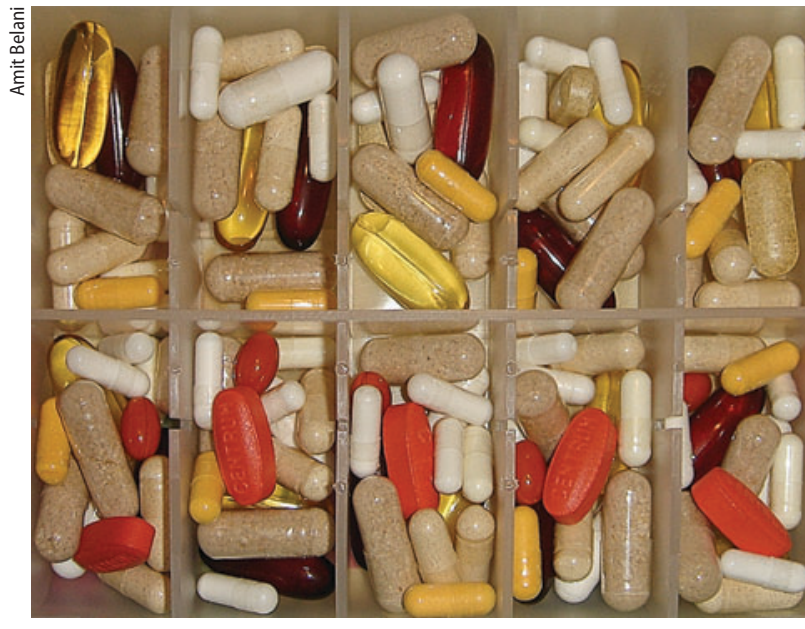

Critical vitamins can be obtained in a variety of foods, or, if necessary, dietary supplements.

snack or beverage 30 to 60 minutes after strenuous, glycogen-depleting exercise. This enhances both glycogen repletion and recovery from strenuous exercise. Depending on the athlete's training volume, carbohydrate requirements range from 6 to 10 grams per kilogram of body weight per day (IOM 2005), generally 50\% to $60 \%$ of total energy intake.

Protein. According to the most current research, the protein needs of athletes not participating in power (such as wrestling and weight lifting) or endurance (such as cross-country running) sports are similar to those of the general population. Therefore, most athletes' protein needs can be met by consuming the recommended level of 0.8 grams per kilogram of body weight per day (IOM 2005). In addition, protein should make up $15 \%$ to $35 \%$ of total calories consumed. However, endurance and power athletes may require higher protein levels, ranging from 1.2 to 1.7 grams per kilogram of body weight per day, or almost twice the amount for sedentary individuals. This ensures that they are getting enough nitrogen, which is required for protein synthesis and muscle repair. To aid in postexercise repair, synthesis and maintenance of skeletal muscle, athletes should consume highquality proteins (those with high bioavailability that contain the essential amino acids) such as soy and animal proteins, including egg and milk products (such as casein and whey).

Fat. Besides yielding a substantial amount of energy, dietary fat provides important fat-soluble vitamins (A, D, E and $\mathrm{K})$ and essential fatty acids. Dietary fat 


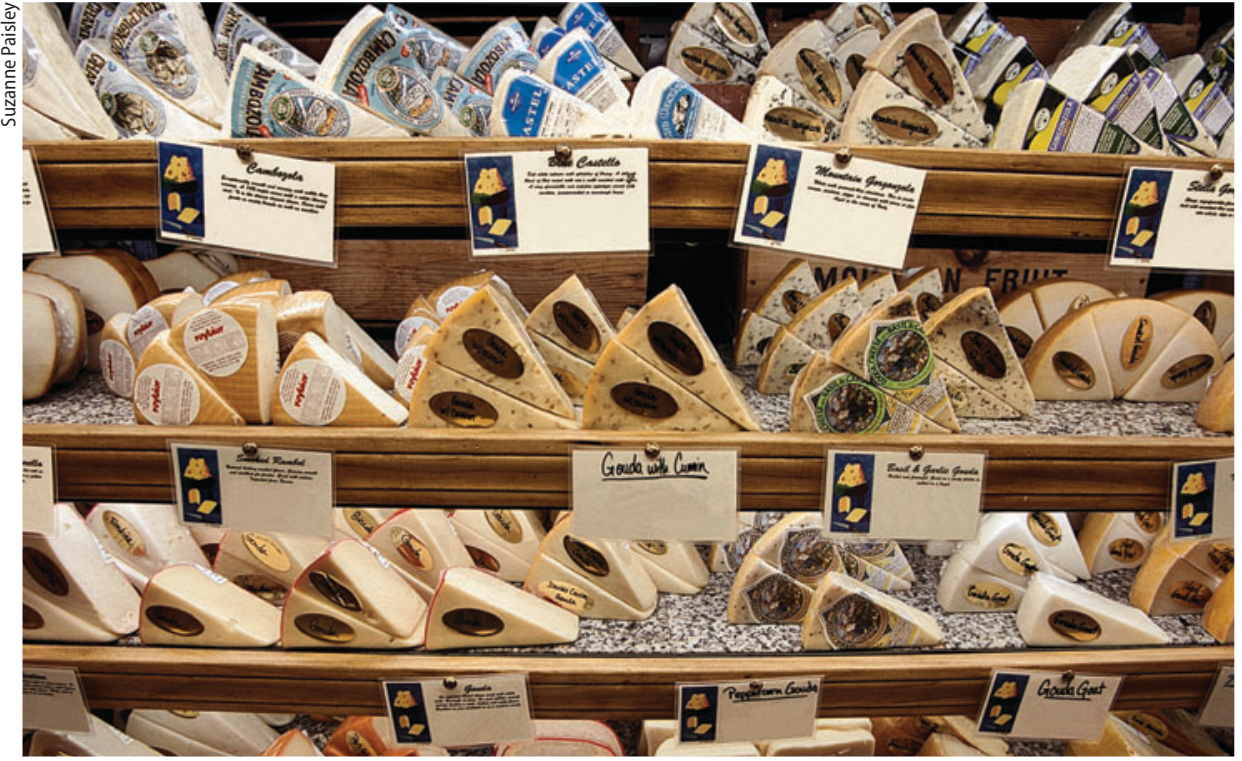

Endurance and power athletes may need twice as much protein as sedentary individuals. After exercise, high-quality proteins, such as those found in dairy products, are critical to muscle repair.

should make up $20 \%$ to $35 \%$ of the total diet and should provide no less than $20 \%$ of total energy needs to benefit athletic performance (Rodriguez et al. 2009).

\section{Vitamins and minerals}

Due to their relatively high metabolic and nutrient needs, athletes should consume diets that provide at least the recommended daily allowance (RDA) for all micronutrients for each individual's respective age group (IOM 2005).

B vitamins. B vitamins facilitate energy metabolism (thiamin, riboflavin, niacin, pyridoxine, pantothenic acid and biotin) and promote muscle repair (folate, vitamin B12). Some reports suggest that the $B$ vitamin requirements of competitive athletes are slightly elevated, and if so these higher needs likely are easily met with increased energy intakes. However, several B vitamins are often low in the diets of female athletes, including riboflavin, pyridoxine, folate and vitamin B12 (IOM 2005; Rodriguez et al. 2009). This can impair performance because severe deficiencies in vitamin B12 or folate can lead to anemia, a condition causing severe fatigue. B vitamin anemia is different from iron-related anemia and can affect the size of red blood cells. Animalderived foods such as red meats and milk are good sources of B vitamins.

Antioxidants. Antioxidant vitamins (such as C, E and the vitamin A precursor beta-carotene) and minerals (such as selenium) protect cell membranes from oxidative damage. These compounds become highly important during periods of increased exercise, particularly endurance-type exercise, since oxygen consumption increases 10 to 15 times with prolonged moderate- to high-intensity aerobic activity (IOM 2005; Manore 2002). Some reports suggest that vitamin E requirements for endurance athletes may be higher than for the general population. Vitamin E supplementation reduces inflammation and muscle soreness, speeding recovery times. It also deters exercise-induced DNA damage. Populations at risk of low vitamin C, vitamin $\mathrm{E}$, beta-carotene and selenium intake are those with diets low in fat, energy, vegetables and whole grains (IOM 2005; Manore 2002); these foods should be incorporated into the diets of all athletes.

Calcium and vitamin D. Calcium serves many important functions and facilitates nerve conduction, muscle contraction, the maintenance of blood calcium levels and the mineralization of bone. Calcium promotes normal growth, development and the maintenance of strong bones. Vitamin D facilitates the absorption of calcium, is important for calcium utilization in the body and improves immune defenses. Female athletes with the highest risk of calcium deficiencies are those with low energy intakes or those who do not meet the dietary recommendation of 3 to 4 servings of dairy foods (such as milk, yogurt and cheese) per day (ACSM et al. 2000). Further, calcium absorption may be hindered due to low estrogen levels in girls and young women exhibiting disordered eating or amenorrhea (Cobb et al. 2003; Gibson et al. 2004; Rodriguez et al. 2009).

The calcium and vitamin D requirements for athletes exhibiting these conditions increase from the normal 1,300 milligrams calcium and 200 IU (international unit) vitamin $\mathrm{D}$ per day, to 1,500 milligrams calcium and 400 to 800 IU vitamin D per day (ACSM et al. 2000). While vitamin $\mathrm{D}$ can be synthesized when skin is exposed to the sun's ultraviolent rays, sunscreens inhibit this natural process, making adequate dietary intake essential.

Iron. Iron is an important mineral for optimal athletic performance due to its role in energy production as well as its oxygen-carrying capacity (ACSM et al. 2000). Iron is a component of the hemoglobin in red blood cells, which transport oxygen to working muscles. Inadequate iron is one of the most common nutritional deficiencies among female athletes and leads to impaired muscle function and reduced performance during workouts and competition (Rodriguez et al. 2009). The iron needs of endurance athletes may be up to $70 \%$ higher than those of the general population (ACSM et al. 2000). Endurance athletes who consume primarily a vegetarian diet take in nonheme iron, a form that is absorbed much less efficiently than heme iron, which is found in red meat (IOM 2005). Female athletes at risk of low iron levels are endurance runners, vegetarians, adolescents and athletes who frequently donate blood (IOM 2005; Rodriguez et al. 2009). The recommendation for iron is 18 milligrams per day and can be obtained most easily from red meats.

Zinc and magnesium. Zinc is important for normal growth, immune function, muscle repair and energy production. Zinc also reportedly influences basal metabolic processes, protein utilization and thyroid hormone function. Low zinc levels have been associated with reduced muscle strength, aerobic function and endurance (IOM 2005; Rodriguez et al. 2009). Female athletes with low animal protein and high fiber intakes are at increased risk of developing zinc deficiency.

Adequate magnesium levels in conjunction with zinc aid performance 
because of their joint roles in facilitating cellular metabolism, and cardiovascular, immune and hormone function. Magnesium deficiencies increase the oxygen required for endurance exercise, hindering performance. Athletes with diets low in energy have been documented to consume low magnesium levels. The daily recommended amounts of zinc and magnesium for adolescents are 12 and 300 milligrams per day, respectively. Readily available sources of these nutrients are animal red meats and milk.

\section{Unique nutritional needs}

Adolescent athletes represent a distinct subpopulation, since their diets must satisfy nutrient requirements for growth and development as well as the demands of their sports. The optimal diet for a young, developing athlete should maximize sport performance, while reducing injury risk and facilitating overall health, growth and maturation. Due to the metabolic and physiologic demands of their sports, the nutrient needs of young athletes can be much higher than their nonathlete peers and higher than the needs of young adult athletes who have reached maturity. It is important to make competitive adolescent athletes aware of their specific needs as well as to identify those athletes at risk of developing deficiencies.

Counseling by a registered dietitian may be necessary to design diets that meets the unique needs of adolescent female athletes. While prior research has provided valuable information about athlete groups with a potential increased risk of developing menstrual disturbances and low bone mass, the majority of studies assessed collegiate and adult athletes and looked at groups at only one point in time. Therefore, it is recommended that future research evaluate adolescents over time to identify the nutritional and exercise behaviors that optimize bone mineral gains and reduce fracture risk. Further, it is necessary to educate athletes, parents, coaches and athletic trainers about behaviors that promote lifetime bone health.

M.T. Barrack is Visiting Researcher, Departmant of Orthopaedic Surgery, UCLA; and M.D. Van Loan is Research Physiologist, U.S. Department of Agriculture, Agricultural Research Service, Western Human Nutrition Research Center, Davis.

This work was supported in part by the UC Davis Center for Health and Nutrition Research, established with funding from the State of California Vitamin Price Fixing Consumer Settlement Fund.

\section{References}

Academy of Eating Disorders. 2011. Prevalence of Eating Disorders. http://www.aedweb.org/Prevalence_of_ ED.htm.

[ACSM et al.] 2000. American College of Sports Medicine American Dietetic Association, and Dietitians of Canada. Joint position statement: Nutrition and athletic performance. Med Sci Sports Exerc 32:2130-45

Barr SI, Janelle KC, Prior JC. 1994. Vegetarian vs. nonvegetarian diets, dietary restraint and subclinical ovulatory disturbances: Prospective 6-month study. Am J Clin Nutr 60:887-94

Barrack MT, Rauh MJ, Barkai HS, Nichols JF. 2008. Dietary restraint and low bone mass in female adolescent endurance runners. Am J Clin Nutr 87:36-43.

Beals KA, Hill AK. 2006. The prevalence of disordered eating, menstrual dysfunction and low bone mineral density among US collegiate athletes. Int J Sport Nutr Exerc Metab 16:1-23.

Beals KA, Manore MM. 2002. Disorders of the female athlete triad among collegiate athletes. Int J Sport Nutr Exerc Metab 12:281-93.

[CIF] California Interscholastic Federation. 2009. High School Sports Participation Remains Steady Despite Economic Downfall. www.cifstate.org

Cobb KL, Bachrach LK, Greendale G, et al. 2003. Disordered eating, menstrual irregularity and bone mineral density in female runners. Med Sci Sports Exerc 35:711-9. Colton M, Gore S. 1991. Risk, Resiliency, and Resistance: Current Research on Adolescent Girls. Ms. Foundation. Gibson JH, Mitchell A, Harries MG, Reeve J. 2004. Nutritional and exercise-related determinants of bone density in elite female runners. Osteoporos Int 15:611-8.

Haskell WL, Lee IM, Pate RR, et al. 2007. Physical activity and public health: Updated recommendation for adults from the American College of Sports Medicine and the American Heart Association. Med Sci Sports Exerc 39:1423-34.

Hasselstrom H, Hansen SE, Froberg K, Andersen LB. 2002 Physical fitness and physical activity during adolescence as predictors of cardiovascular disease risk in young adulthood. Danish Youth and Sports Study. An eight-year follow-up study. Int J Sports Med 23(Suppl 1):S27-31.
Hilton LK, Loucks AB. 2000. Low energy availability, not exercise stress, suppresses the diurnal rhythm of leptin in healthy young women. Am J Physiol Endocrinol Metab 278:E43-9.

Hulley AJ, Hill AJ. 2001. Eating disorders and health in elite women distance runners. Int J Eat Disord 30(3):312-7.

Ihle R, Loucks AB. 2004. Dose-response relationships between energy availability and bone turnover in young exercising women. J Bone Miner Res 19:1231-40.

[IOM] Institute of Medicine. 2005. Dietary Reference Intakes for Energy, Carbohydrates, Fiber, Fat, Fatty Acids, Cholesterol, Protein and Amino Acids. Food and Nutrition Board. Washington, DC: Nat Acad Pr. 1,331 p.

Kemper HC, Post GB, Twisk JW, van Mechelen W. 1999. Lifestyle and obesity in adolescence and young adulthood: Results from the Amsterdam Growth and Health Longitudinal Study (AGAHLS). Int J Obes Relat Metab Disord 23(Suppl 3):S34-40

Kulig K, Brener ND, McManus T. 2003. Sexual activity and substance use among adolescents by category of physical activity plus team sports participation. Arch Pediatr Adolesc Med 157:905-12.

Loucks AB. 2006. The response of luteinizing hormone pulsatility to 5 days of low energy availability disappears by 14 years of gynecological age. J Clin Endocrinol Metab 91:3158-64.

Loucks AB, Heath EM. 1994. Induction of low-T3 syndrome in exercising women occurs at a threshold of energy availability. Am J Physiol 266:R817-23.

Loucks AB, Thuma JR. 2003. Luteinizing hormone pulsatility is disrupted at a threshold of energy availability in regularly menstruating women. J Clin Endocrinol Metab 88:297-311

Manore MM. 2002. Dietary recommendations and athletic menstrual dysfunction. Sports Med 32:887-901.

McLean JA, Barr SI, Prior JC. 2001. Dietary restraint, exercise and bone density in young women: Are they related? Med Sci Sports Exerc 33:1292-6.

Mudd LM, Fornetti W, Pivarnik JM. 2007. Bone minera density in collegiate female athletes: Comparisons among sports. J Athl Train 42:403-8.

[NCAA] National Collegiate Athletic Association. 2005. Graduation-rates Report for NCAA Division I Schools. www.aauw.org/act/laf/library/athleticStatistics.cfm.
[NCWGE] National Coalition for Women and Girls in Education. 2008. Beyond the Headlines. American Association of University Women. Washington, DC.

Nichols JF, Rauh MJ, Barrack MT, et al. 2007. Disordered eating and menstrual irregularity in high school athletes in lean-build and nonlean-build sports. Int J Sport Nutr Exerc Metab 17:364-77.

Nichols JF, Rauh MJ, Lawson MJ, et al. 2006. Prevalence of the female athlete triad syndrome among high school athletes. Arch Pediatr Adolesc Med 160:137-42.

Rodriguez NR, DiMarco NM, Langley S. 2009. Position of the American Dietetic Association, Dietitians of Canada, and the American College of Sports Medicine: Nutrition and athletic performance. J Am Diet Assoc 109:509-27.

Stipanuk MH. 2000. Biochemical and Physiological Aspects of Human Nutrition (1st ed.). Philadelphia, PA: WB Saunders. 1,007 p.

Thompson SH. 2007. Characteristics of the Female Athlete Triad in collegiate cross-country runners. J Am College Health 56:129-36.

Torstveit MK, Sundgot-Borgen J. 2005a. Participation in leanness sports but not training volume is associated with menstrual dysfunction: A national survey of 1276 elite athletes and controls. Br J Sports Med 39:141-7.

Torstveit MK, Sundgot-Borgen J. 2005b. The female athlete triad exists in both elite athletes and controls. Med Sci Sports Exerc 37:1449-59.

van Hooff MH, Voorhorst FJ, Kaptein MB, et al. 1998. Relationship of the menstrual cycle pattern in 14-17-year-old adolescents with gynaecological age, body mass index and historical parameters. Hum Reprod 13:2252-60.

Warren MP, Chua AT. 2008. Exercise-induced amenorrhea and bone health in the adolescent athlete. Ann NY Acad Sci 1135:244-52.

Williams NI, Helmreich DL, Parfitt DB, et al. 2001. Evidence for a causal role of low energy availability in the induction of menstrual cycle disturbances during strenuous exercise training. J Clin Endocrinol Metab 86:5184-93.

Yeager KK, Agostini R, Nattiv A, Drinkwater B. 1993. The female athlete triad: Disordered eating, amenorrhea osteoporosis. Med Sci Sports Exerc 25(7):775-7. 